\title{
Análise dos danos estruturais e das condições de estabilidade da Ponte da Estrada Velha de Água Fria
}

Title: Analysis of structural damages and stability conditions of the Estrada Velha de Água Fria street bridge

\author{
Jhonata William Lopes \\ Escola Politécnica de Pernambuco \\ Universidade de Pernambuco \\ 50.720-001 - Recife, Brasil \\ tecnologojonatha@gmail.com
}

\author{
José Afonso Pereira Vitório \\ Escola Politécnica de Pernambuco \\ Universidade de Pernambuco \\ 50.720-001 - Recife, Brasil \\ afonsovitorio@gmail.com
}

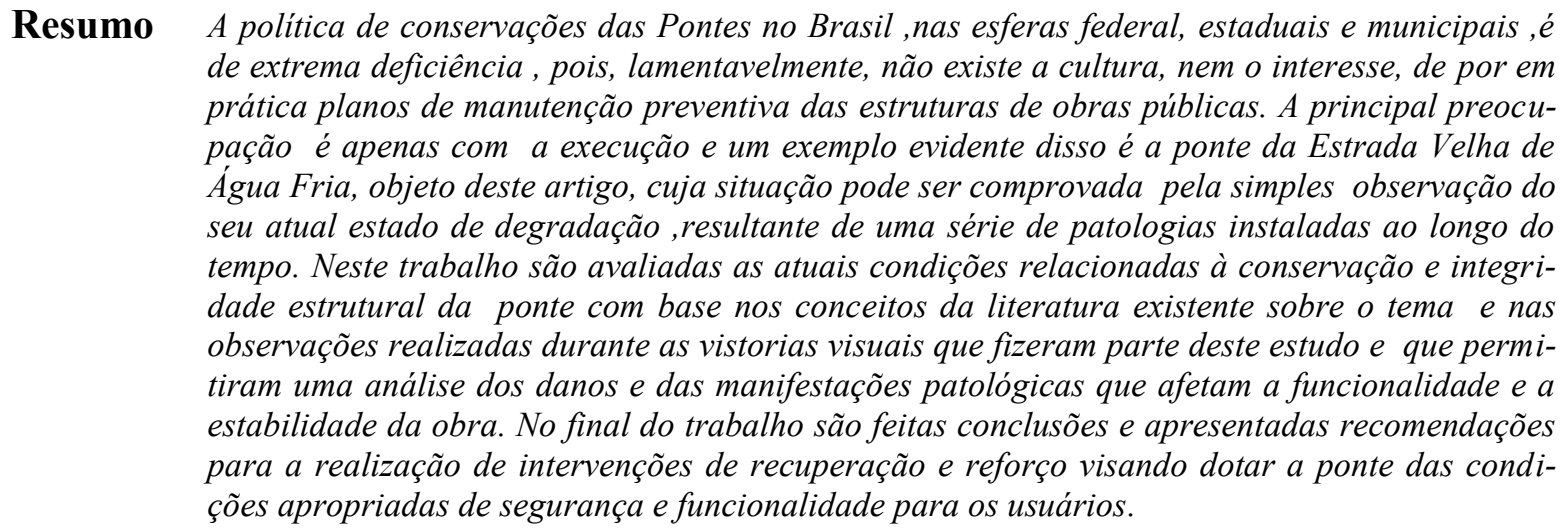

Palavras-Chave: Pontes, Conservação, Vistorias, Estruturas

\begin{abstract}
The conservations policy of bridges in Brazil ,in the federal, state and municipal spheres is extreme deficiency because lamentably, doesn't exist the culture, or interest, to put into practice preventive maintenance plans of public works structures. The main concern is only with the execution and an clear example of this is the bridge from Estrada Velha of Água Fria, the object of this article, whose situation can be proven by the simple observation of your current degradation state, resulting in a series of pathologies installed over time. In this work are evaluated current conditions related to the conservation and structural integrity of the bridge based on literature concepts existing about the subject and in the observations made during visual inspections that were part of this study and allowed an analysis of the damage and pathological manifestations that affects the functionality and the stability of the work. In the end of the work the conclusions are made and presented recommendations for performing interventions of the recovery and reinforcement aiming to provide the bridge with the appropriate conditions of security and functionality for users.
\end{abstract}

Keywords: Bridges, Conservation, Surveys, Inspections, Structures 


\section{Introdução}

As primeiras pontes foram, provavelmente, o resultado natural da colocação de troncos de árvores sobre rios e sobre outros obstáculos criados pela natureza entre dois espaços, para que o homem pudesse continuar o seu trajeto $[1]$.

Ao longo dos séculos, as pontes foram sendo aperfeiçoadas pelo homem com o uso de materiais e técnicas cada vez mais sofisticadas para facilitar o comércio, o transporte, as guerras, e as viagens, entre outros. Algumas delas têm se tornado ícones, símbolos do melhor que a engenharia civil pode oferecer [2].

O surgimento do cimento Portland no século XIX, as variedades de concreto e de outros materiais e técnicas de construção deram à engenharia o poder de fabricar pontes com vãos cada vez maiores [1]. Nessa época inicial, pensava-se que o concreto teria durabilidade ilimitada, mas com o passar das décadas verificou-se que o concreto, assim como outros materiais, sofre com a degradação produzida por fissuras, corrosão, elementos climáticos, poluição e a ação destruidora do homem, entre outros. De modo geral, as pontes têm dado verdadeiros exemplos de grande durabilidade, muitas vezes em condições totalmente adversas, mas a vida útil de tais obras é definitivamente finita como a da grande maioria dos bens produzidos no planeta.

Nesse sentido, o Sindicato das Empresas de Arquitetura e de Engenharia Consultiva, SINAENCO, realizou entre 2006 e 2008 uma campanha pela manutenção do ambiente construído, denominada "Infraestrutura de Pernambuco-Prazo de Validade Vencido", com o objetivo de identificar os principais problemas de pontes, viadutos, rodovias, galerias e canais, de modo a avaliar o estado de deterioração da infraestrutura de Pernambuco. A campanha inspecionou diversas obras em Pernambuco e mostrou que as maiores causas das avarias observadas eram consequência da falta de conservação por parte do poder público. [3].

Uma das obras que fizeram parte da referida campanha foi a ponte localizada sobre o Canal do Arruda, na Estrada Velha de Água Fria que é objeto deste estudo. Trata-se de uma ponte de concreto armado, pertencente à malha viária da cidade do Recife, cuja data de construção não foi possível de identificar. Porém as características estruturais e construtivas indicam que deve ter sido construída entre as décadas de 1960 e 1970 do século passado. A ponte, localizada na II Perimetral, uma importante via para o trânsito do Recife, passa por um avançado processo de desgaste estrutural e necessita passar por intervenções de recuperação para que possa atender às finalidades estruturais e funcionais de uma Obra de Arte Espe- cial. Este trabalho se propõe portanto, a identificar as principais manifestações patológicas e danos estruturais, emitindo diagnóstico e propondo a correção das avarias identificadas.

\section{Metodologia}

Este trabalho foi desenvolvido com base nas observações efetuadas durante as vistorias visuais realizadas na estrutura da ponte. A partir das informações obtidas nas vistorias, procedeu-se a uma análise dos danos e manifestações patológicas de modo a permitir caracterizar o estado atual da obra, respaldado pelos conceitos que constam da literatura técnica sobre este tema e que fazem parte da revisão bibliográfica deste texto. O trabalho também sugere a adoção de medidas para corrigir as anomalias identificadas e dotar a ponte das condições apropriadas de estabilidade e funcionalidade.

\section{Conceitos da Literatura Técnica Aplicados a este Estudo}

A seguir são apresentados os conceitos de durabilidade e vida útil e dos fenômenos patológicos mais conhecidos na literatura técnica que estão diretamente relacionados aos mecanismos de deterioração das estruturas de concreto armado e que em sua grande maioria, foram identificados na ponte que se constitui no estudo de caso deste artigo.

\subsection{Durabilidade e vida útil}

A durabilidade de uma estrutura de concreto está relacionada a uma série de parâmetros que dependem do projeto estrutural, dos materiais utilizados, da qualidade da execução da obra, da agressividade ambiental, do uso e do tipo de conservação.

Esses parâmetros interferem diretamente nos mecanismos responsáveis pela degradação das estruturas, como é o caso da permeabilidade, baixa resistência do concreto, cobrimento insuficiente de armaduras, etc.

A vida útil por sua vez é o período de tempo no qual uma estrutura é capaz de desempenhar as funções para as quais foi projetada sem a necessidade de intervenções não previstas. Existem vários modelos para prever a vida útil das estruturas expostas a determinados mecanismos de degradação em ambientes agressivos, como é o caso das pontes. Tais modelos devem fornecer aos projetistas estruturais as informações suficientes para avaliar as mudanças que certamente ocorrerão ao longo do tempo de utilização da obra [4]. A tabela 1 mostra os principais mecanismos de degradação das estruturas de concreto armado, inclusive das pontes. 


\begin{tabular}{|c|c|c|c|}
\hline \multicolumn{2}{|c|}{$\begin{array}{l}\text { AGRESSIVIDADE DO } \\
\text { AMBIENTE }\end{array}$} & \multicolumn{2}{|c|}{$\begin{array}{c}\text { CONSEQUÊNCIAS SOBRE A } \\
\text { ESTRUTURA }\end{array}$} \\
\hline $\begin{array}{l}\text { Natureza } \\
\text { do pro- } \\
\text { cesso }\end{array}$ & $\begin{array}{l}\text { Natureza } \\
\text { do pro- } \\
\text { cesso }\end{array}$ & $\begin{array}{l}\text { Alterações } \\
\text { iniciais na } \\
\text { superfície } \\
\text { concreto }\end{array}$ & $\begin{array}{l}\text { Efeitos em } \\
\text { longo prazo }\end{array}$ \\
\hline $\begin{array}{l}\text { Carbona- } \\
\text { tação }\end{array}$ & $\begin{array}{l}\text { UR } 60 \text { a } \\
85 \%\end{array}$ & $\begin{array}{l}\text { Imperceptí- } \\
\text { vel }\end{array}$ & $\begin{array}{l}\text { Redução do } \\
\text { pH } \\
\text { Corrosão de } \\
\text { armaduras } \\
\text { Desagrega- } \\
\text { ção super- } \\
\text { ficial }\end{array}$ \\
\hline $\begin{array}{l}\text { Lixivia- } \\
\text { ção }\end{array}$ & $\begin{array}{l}\text { Atmosfera } \\
\text { ácida, } \\
\text { águas } \\
\text { puras }\end{array}$ & $\begin{array}{l}\text { Eflorescên- } \\
\text { cias, man- } \\
\text { chas bran- } \\
\text { cas }\end{array}$ & $\begin{array}{l}\text { Redução do } \\
\text { pH } \\
\text { Corrosão de } \\
\text { armaduras } \\
\text { Desagrega- } \\
\text { Ção super- } \\
\text { ficial }\end{array}$ \\
\hline Retração & $\begin{array}{l}\text { Umedeci- } \\
\text { mento e } \\
\text { secagem, } \\
\text { ausência } \\
\text { de cura, } \\
\text { UR baixa } \\
(<50 \%)\end{array}$ & $\begin{array}{l}\text { Manchas } \\
\text { escuras }\end{array}$ & $\begin{array}{l}\text { Redução do } \\
\text { Ph } \\
\text { Corrosão de } \\
\text { armaduras }\end{array}$ \\
\hline $\begin{array}{l}\text { Fungos e } \\
\text { mofo }\end{array}$ & $\begin{array}{l}\text { Altas } \\
\text { tempera- } \\
\text { turas (> } \\
20^{\circ} \text { e } \\
\left.>50^{\circ}\right) \text { com } \\
\text { UR > }>75 \%\end{array}$ & $\begin{array}{l}\text { Manchas } \\
\text { escuras e } \\
\text { esverdeadas }\end{array}$ & $\begin{array}{l}\text { Redução do } \\
\text { pH } \\
\text { Desagrega- } \\
\text { ção super- } \\
\text { ficial } \\
\text { Corrosão de } \\
\text { armaduras. }\end{array}$ \\
\hline $\begin{array}{l}\text { Concen- } \\
\text { tração } \\
\text { salina, } \\
\text { Cl }\end{array}$ & $\begin{array}{l}\text { Atmosfe- } \\
\text { ras mari- } \\
\text { nha e } \\
\text { industri- } \\
\text { al }\end{array}$ & $\begin{array}{l}\text { Imperceptí- } \\
\text { vel }\end{array}$ & $\begin{array}{l}\text { Despassiva- } \\
\text { Ção e cor- } \\
\text { rosão de } \\
\text { armaduras }\end{array}$ \\
\hline Sulfatos & $\begin{array}{l}\text { Esgoto e } \\
\text { águas } \\
\text { servidas }\end{array}$ & Fissuras & $\begin{array}{l}\text { Expansão } \\
\text { fissuras } \\
\text { Desagrega- } \\
\text { ção do } \\
\text { concreto } \\
\text { Corrosão de } \\
\text { armaduras }\end{array}$ \\
\hline $\begin{array}{l}\text { Álcali- } \\
\text { agregado }\end{array}$ & $\begin{array}{l}\text { Composi- } \\
\text { ção do } \\
\text { concreto } \\
\text { Umidade, } \\
\text { UR > 95\% }\end{array}$ & $\begin{array}{l}\text { Fissuras } \\
\text { Gel ao } \\
\text { redor do } \\
\text { agregado } \\
\text { graúdo }\end{array}$ & $\begin{array}{l}\text { Expansão } \\
\rightarrow \text { fissuras } \\
\text { Desagrega- } \\
\text { Ção do } \\
\text { concreto } \\
\text { Corrosão de } \\
\text { armaduras }\end{array}$ \\
\hline
\end{tabular}

Figura 1 - Vista lateral da ponte.

\section{Estudo de Caso}

\subsection{Descrição da ponte estudada}

Ao contrário de outras pontes mais famosas ou pelo menos mais conhecidas da cidade do Recife, a ponte da Estrada Velha de Água Fria, sobre o canal do Arruda, não tem um nome próprio, apenas o indicativo da sua localização, um bairro na Zona Norte do Recife, que um dia já foi famoso pela congregação. A ponte, que mede $11,30 \mathrm{~m}$ de comprimento e $25,25 \mathrm{~m}$ de largura tem um tabuleiro constituído por laje maciça de concreto armado de aproximadamente $0,62 \mathrm{~m}$ na parte interna e alargada para $1,10 \mathrm{~m}$ nas duas extremidades onde estão localizados os passeios de pedestres, cada um com 2,55m de largura.

Sobre o tabuleiro existem duas faixas de rolamento, cada uma com $9,00 \mathrm{~m}$ e um canteiro central com $2,05 \mathrm{~m}$. As figuras 1 e 2 mostram duas vistas que ressaltam os aspectos laterais da ponte.

Como praticamente todas as pontes do Recife, a ponte objeto deste estudo apresenta uma longa lista de patologias causadas pela ação do tempo, a agressividade ambiental, o uso indevido, a negligência e a falta de manutenção.

A seguir são apresentadas as principais manifestações patológicas e danos estruturais observados durante as vistorias realizadas na superestrutura, mesoestrutura e infraestrutura.

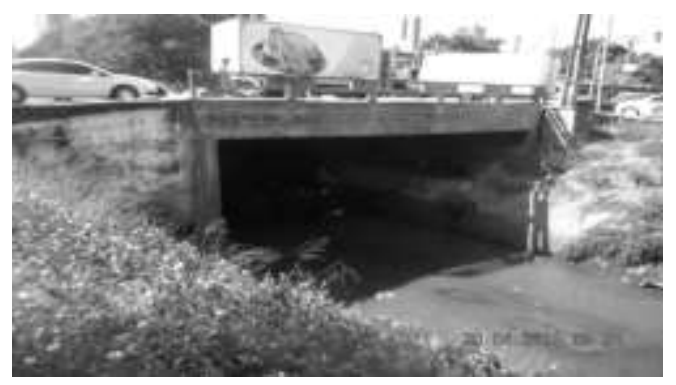

Figura 1 - Vista lateral da ponte.

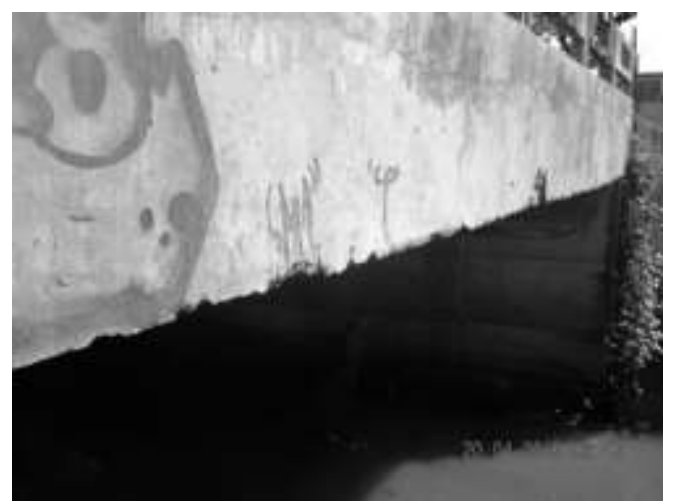

Figura 2 - Detalhe da espessura lateral da laje. 


\subsection{Principais danos e manifestações patoló- gicas existentes na superestrutura}

\subsubsection{Bolor na face inferior da laje do tabuleiro}

Observa-se na Figura 3 a presença de Bolor na superfície inferior da laje do tabuleiro.. Estudos mostram que determinados intervalos de temperatura e de umidade relativa do ar possibilitam a formação de mofo e bolor. Taxas de umidade relativa do ar acima de $80 \%$, com temperaturas acima de $10^{\circ} \mathrm{C}$ são condições ideais para a formação das mais de 200 espécies existentes de mofo e bolor. Atualmente a norma NBR 15220-2003 define os parâmetros a serem respeitados para o desempenho térmico das edificações.

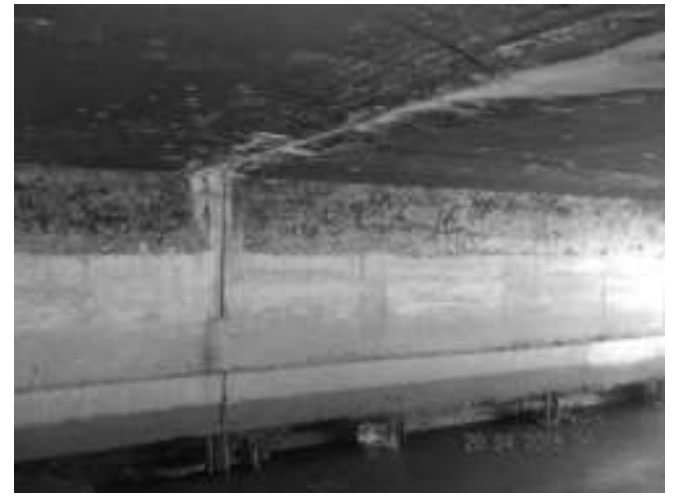

Figura 3 - Formação de bolor e mofo na laje do tabuleiro.

\subsubsection{Calcinação}

A Figura 4 , mostra a calcinação da estrutura do tabuleiro causada por fogueiras acesas por pessoas sem teto. A calcinação resseca as camadas superficiais, altera a cor do concreto e reduz a sua resistência. De modo geral, a degradação inicia-se a partir dos $600 \square \mathrm{C}$, por expansão dos agregados que desenvolvem tensões internas e fraturam o concreto. A intensidade da calcinação indica que a submissão da estrutura a altas temperaturas provocadas pelo fogo sob a ponte parece ter uma grande frequência.

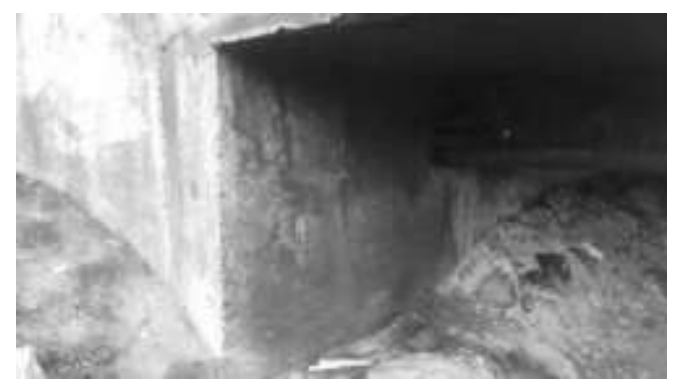

Figura 4 - Calcinação da estrutura causada por fogueiras sob a ponte.

\subsubsection{Efeitos da Infiltração de água}

É possível observar na Figura 5 a falta de pingadeiras, que são elementos importantes para evitar que a água escoe pela lateral do tabuleiro, e crie condições propícias para a infiltração que por sua vez causa desgaste e perda da resistência do concreto, além do desenvolvimento de mofos e bactérias. Segundo Vitório [5] "mesmo a água totalmente pura, como é o caso das águas de chuvas nas pontes, pode atacar o concreto através da infiltração e do acumulo ao longo do tempo devido à ausência de pingadeiras e da deficiência das juntas e da drenagem do tabuleiro.

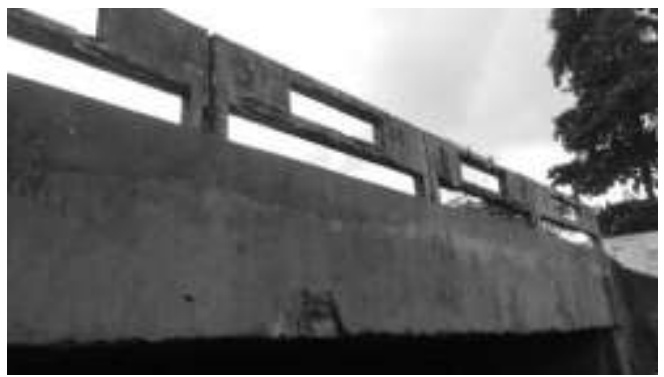

Figura 5 - Ausência de pingadeiras na borda da laje do tabuleiro da ponte.

\subsubsection{Falhas de concretagem}

Como pode ser visto na Figura 6, existe claras evidencias de falhas de concretagem nas faces inferiores e laterais do tabuleiro da ponte ( o concreto aparenta ser altamente poroso). $\mathrm{O}$ tamanho e a distribuição dos poros (porosidade) tem grande influência na capacidade do concreto de suportar o efeito de agentes agressivos como água, oxigênio, dióxido de carbono, cloretos e outros.

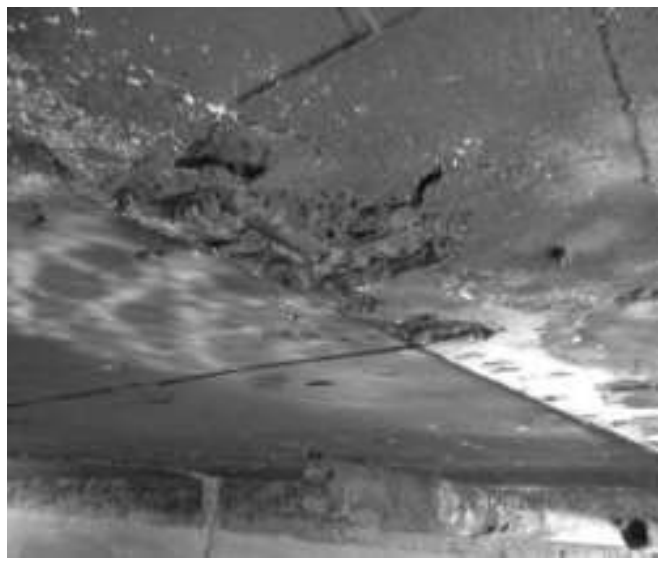

Figura 6 - Falhas de concretagem oriundas de má execução da vibração do concretagem.

\subsubsection{Desplacamento do concreto}

Na Figura 7 é possível observar este fenômeno que ocorre devido as pressões de expansão superiores a 15 Mpa no processo da pilha eletroquímica oriunda basicamente na presença de água, oxigênio e variação de temperatura, área anódica e catódica, um condutor metálico e um eletrólito [6].

Isso acarreta a oxidação do concreto que aumenta em 
volume e o expele do cobrimento expondo a armadura à ação agressiva do meio ambiente. A continuidade desse fenômeno pode acarretar o total comprometimento estrutural da armação.

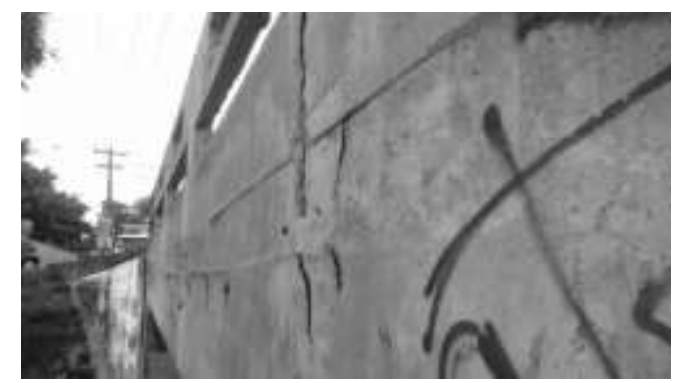

Figura 7 - Desplacamento do cobrimento do concreto que envolve a armadura lateral do tabuleiro.

\subsubsection{Baixa espessura da camada de cobrimento da armadura}

Na Figura 8 observa-se o que o cobrimento do concreto da superfície inferior do tabuleiro tem menos de $1 \mathrm{~cm}$, deixando o aço desprotegido e passível de corrosão. As tensões internas no concreto causam fissuras e o afastamento da camada de cobrimento facilitando assim a entrada de mais agentes agressivos. É importante ressaltar que a norma vigente à época em que a ponte foi construí$\mathrm{da}$, previa cobrimentos da ordem de apenas $1,5 \mathrm{~cm}$. Atualmente a NBR 6118/2014 exige para cobrimento nominal da armadura, espessura de até $5 \mathrm{~cm}$ para a ponte em estudo (classe de agressividade IV, as superfícies do concreto expostas aos agentes agressivos do meio ambiente como, reservatórios, estações de tratamento de água, esgoto, condutores de esgoto, canaletas de efluentes).

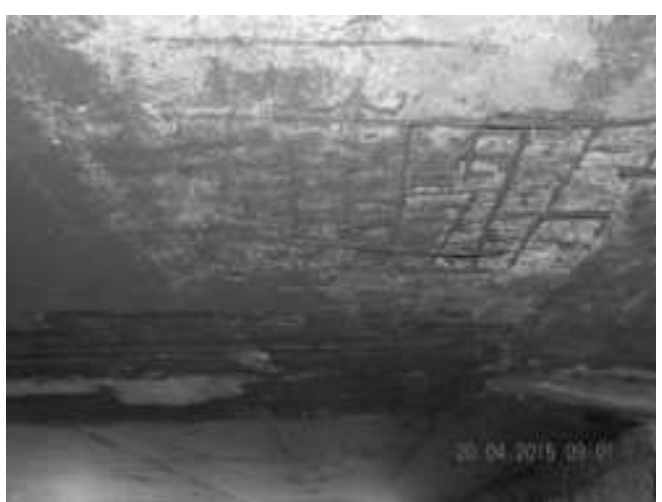

Figura 8 - Baixa espessura da camada de cobrimento da armadura, causando a exposição das mesmas.

\subsubsection{Problemas diversos}

Existem ainda outros problemas em componentes diversos relacionados à superestrutura, como a situação mostrada na Figura 9, que refere-se a um grande desnível no passeio de pedestres, causado pelo abatimento do solo, provavelmente decorrente de uma má compactação.

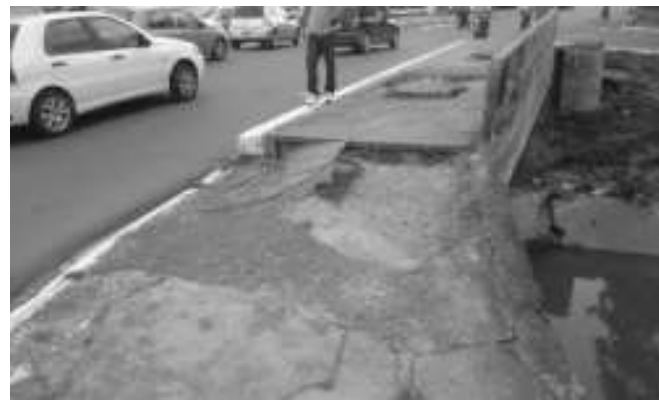

Figura 9 - Deformação do solo da passagem de pedestres.

Outra questão, mostrada na Figura 10, refere-se aos guarda corpos da ponte cujas armaduras estão expostas aos agentes agressivos do meio. É fácil perceber que não foram utilizados espaçadores para cobrimento adequado na fase de execução, pois o aço está faciado com o concreto.

Outro problema que não pode deixar de ser relatado é o uso indevido da ponte para a transposição de tubulações penduradas no tabuleiro e fixadas por meio de chumbadores. Observa-se que a fixação inadequada desses chumbadores contribuiu para acentuar ainda mais os danos estruturais no concreto ao longo do tempo. Outra consequência da colocação de tais tubulações é o estrangulamento da seção de cazão do canal sob a ponte. Esse problema está mostrado na Figura 11.

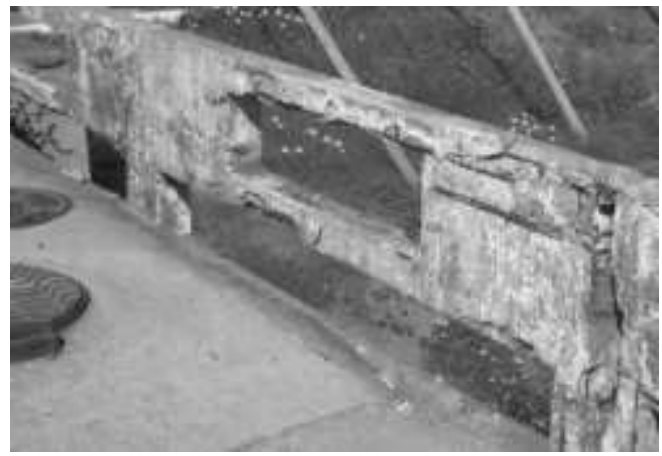

Figura10 - Guarda corpos danificados.

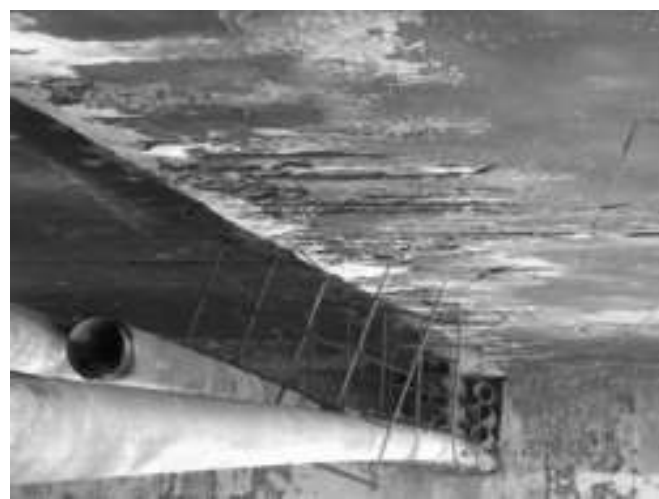

Figura 11 - Tubulações fixadas inadequadamente no tabuleiro da ponte. 


\subsection{Principais Problemas na Mesoestrutura}

A mesoestrutura, constituída pelos encontros de concreto armado, apresenta como principais problemas algumas falhas de concretagem e lixiviação do concreto causada pela variação das marés ao longo do tempo. Observa-se que de um dos lados da ponte existe uma espécie de talude entre o encontro e a parede do canal, que além de obstruir a seção de vazão também serve de abrigo eventual para pessoas que entre outras coisas, provocam os pequenos incêndios que estão calcinando a estrutura. Esses taludes encontram-se atualmente erodidos e podem ser vistos na Figura 12.

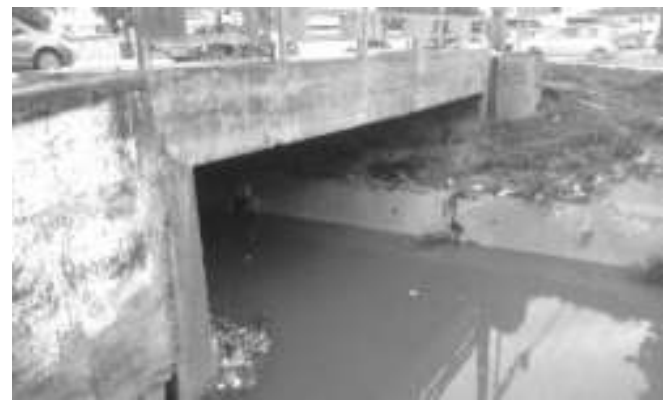

Figura 12 - Erosão no talude sob um dos lados da ponte.

\subsubsection{Deslocamento entre o tabuleiro e o encontro da ponte}

Também foi observado um deslocamento vertical entre um dos encontros e o tabuleiro, conforme mostra a Figura 13. Observa-se que na extremidade do tabuleiro sobre o encontro da ponte existe uma abertura e essa região está propícia para a entrada das águas de chuva e posteriores patologias decorrentes dos agentes agressivos

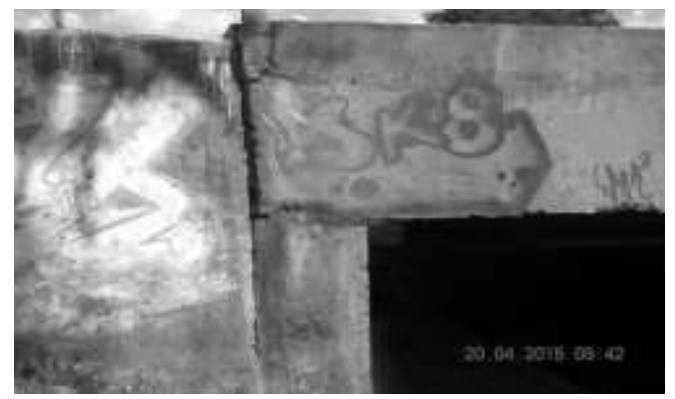

Figura 13 - Detalhe do deslocamento do tabuleiro com o encontro.

\subsection{Principais problemas na Infraestrutura}

Nas figuras 14 e 15 observa-se além do acúmulo de lixo, estacas metálicas expostas e com parte fora da água em zona de variação de maré. Essa situação gera um efeito deletério por causa dos agentes agressivos como os ácidos, os sulfatos, o cloro e seus compostos, os nitratos e nitritos que passam a agredir os perfis metálicos que compõem as estacas.

Basicamente para que ocorra a corrosão das estacas é necessário que se tenha uma região anódica para corroer, uma área catódica para alimentar a região anterior, um caminho externo composto por uma solução ou eletrólito, uma ligação eletrônica ou caminho interno pelo próprio aço para completar o circuito.

As corrosões das estacas acontecem na superfície do material metálico: na parte anódica do metal ocorre a oxidação e na região catódica ocorre a redução do material. É desenvolvido um potencial elétrico nas áreas anódicas e catódicas, assim fechando um circuito elétrico completo. Existe atualmente, uma grande quantidade de literaturas que indicam que os solos naturais se caracterizam por significativa ausência de oxigênio, de modo que a corrosão do aço fica praticamente nula, ou seja, fatores relacionados ao tipo de solo, drenagem, resistividade elétrica, $\mathrm{PH}$, ou composição química não tem importância considerável no processo de corrosão de estacas metálicas completamente enterradas [7].

Ocorre um processo acentuado e acelerado de corrosão na zona da estaca metálica onde ocorre a variação do nível da água do canal. O grau de agentes agressivos na água tais como sais e cloretos, aceleram de forma muito significativa o processo de corrosão nessa região, pois as moléculas de oxigênio nesta estão muito mais presentes do que na região em as estacas estão aterradas [7] .

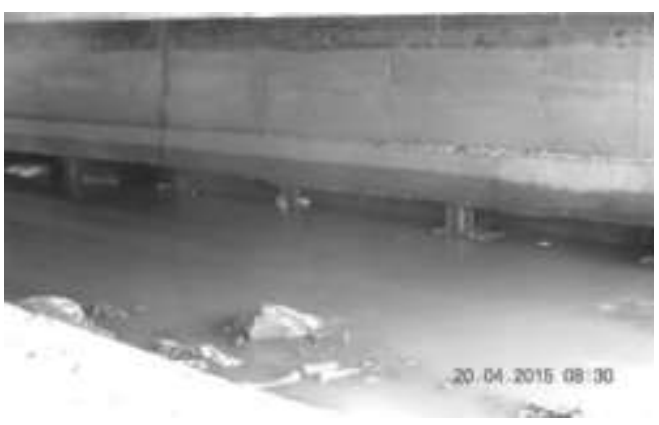

Figura 14 - Estacas metálicas expostas em área de variação de mares

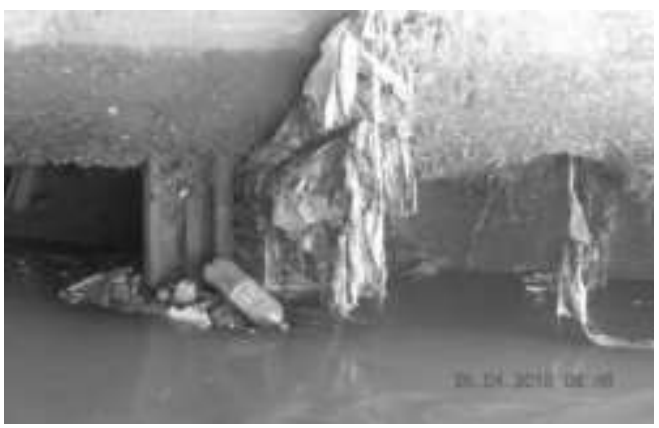

Figura 15 - Estacas metálicas com grande acúmulo de lixo. 


\section{Conclusões e Recomendações}

\subsection{Conclusões}

O estudo de caso apresentado neste artigo é uma pequena demonstração da ausência de manutenção, seguidade reforço e reabilitação estrutural, quando necessário. As patologias apresentadas na ponte da Estrada Velha de Água Fria foram em grande parte decorrentes da ausência de manutenção ao longo do tempo e da cultura do setor público, nos âmbitos federal, estaduais e municipais, em não investir em atividades relacionados à conservação de obras de infraestrutura. É de extrema importância que hajam intervenções de manutenções periódicas pois o custo desse item está diretamente relacionado à urgência com que a intervenção é feita. $O$ custo das obras voltadas para medidas preventivas e corretivas será significativamente menor se essas medidas forem tomadas o quanto antes. Quando uma patologia ou um dano estrutural ocorre, será apenas uma questão de tempo para que o quadro patológico se agrave. Em casos de armaduras expostas, a situação pode ser ainda mais grave, pois a estrutura da obra fica desprotegida dos agentes agressivos presentes no meio ambiente.

Constata-se que as partes estruturais mais danificadas na ponte da Estrada Velha de Água Fria estão localizadas em áreas de maior umidade e variação de nível da água do canal, onde grande é a penetração de agentes agressivos através da porosidade do concreto, possibilitando um ambiente favorável para manifestações patológicas relacionadas à corrosão de armaduras e dos perfís metálicos das estacas da fundação existente. A falta de cobrimento adequado das armaduras na estrutura como um todo e a ausência de proteção das estacas com pintura ante corrosiva ou com o emcamisamento com chapas de aço na fase de construção da ponte, são fatores que influíram consideravelmente no processo de deterioração da obra ao longo do tempo.

É importante ressaltar que não foi possível identificar riscos visíveis de colapso iminente da ponte da Estrada Velha de Água Fria, considerando as limitações da inspeção visual realizada. Também não é possível afirmar que tais riscos não existam.

\subsection{Recomendações}

\subsubsection{Superestrutura e mesoestrutura de concreto}

A partir do conhecimento geral sobre as avarias existentes na ponte da Estrada Velha de Água Fria é possível apresentar algumas recomendações para solucionar o quadro patológico existente que, no caso da estrutura de concreto deverão constar de serviços de recuperação e reforço estrutural.

Para início dos serviços de recuperação estrutural, faz-se necessário a montagem do canteiro de obras e ligações provisórias. Após esta etapa concluída, inicia-se a montagem da plataforma de trabalho, fixada, no fundo do tabuleiro da ponte, para possibilitar executar o apicoa mento manual ou mecânico da superfície do concreto; após esta etapa, inicia-se o processo de jateamento com água das áreas apicoadas, retirando todo o resíduo de poeira da superfície e garantindo uma qualidade superior para a aderência entre concreto velho e novo.

Para recuperar a calçada deve ser feita a substituição do solo existente por um material importado CBR $>10 \%$. Esse material deve ser devidamente compactado em camadas não superiores a $20 \mathrm{~cm}$. O descarte adequado dos entulhos provenientes de todas as etapas da reabilitação estrutural da ponte devem seguir todo o processo ambiental e legal

É necessário fazer uma avaliação técnica das armaduras corroídas e do concreto da ponte. Ensaios de carbonatação e extração de testemunhos de concreto serão de grande valia nesse sentido. Após a coleta dos dados e rompimento dos corpos de prova, as informações serão fundamentais para que o engenheiro estrutural faça o projeto de reabilitação estrutural da ponte. Também deve ser feita a avaliação das armaduras que foram possivelmente danificadas ou rompidas pelas fixações das tubulações pelas companhias de água, de telefonia, etc, pelo fato de tais aberturas terem sido fixadas sem nenhum tipo planejamento.

Não foram observadas juntas de dilatação na faixa de rolamento da ponte; talvez seja necessário a execução de lábios poliméricos e selantes para caracterizar efetivamente uma junta, inclusive para efeito de vedação, pois não fora identificados dispositivos para a drenagem do tabuleiro, como é o caso dos drenos recomendados pelo DER e DNIT, implantados nos bordos do tabuleiro com um espaçamento mínimo da ordem de $3 \mathrm{~m}$.

\subsubsection{Fundações em estacas metálicas.}

Para a análise das fundações, a primeira providência a ser tomada deverá ser uma inspeção nas estacas metálicas de modo a avaliar a integridade estrutural das mesmas. É necessário avaliar o grau de corrosão em que as estacas se encontra, realizar testes de integridade e a da perda de seção transversal. Caso as estacas não atendam aos requisitos mínimos definidos nas normas e não tenham mais a capacidade de carga exigida, deve ser feito reforço de fundação com a cravação de novas estacas ao lado das existentes e por último, executar blocos de encamisamentos, envolvendo os blocos existentes. Essa solução é a mais apropriada diante da impossibilidade técnica de aplicar pintura anticorrosiva ou fazer jaqueteamento nas estacas existentes. A cravação de novas estacas de reforço, proporcionará uma nova distribuição das cargas da ponte no estaqueamento de modo a transmitir 
cargas menores e compatíveis com a capacidade resistente das estacas existentes. O tipo de estaca a ser utilizado para o reforço será definido pelo projetista estrutural e deverá considerar as peculiaridades inerentes a ponte estudada.

É importante ressaltar que as estacas estão em zona de variação do nível da água do canal e nessa região existe a presença de umidade e oxigênio, fatores esses que são favoráveis à corrosão. Também é importante destacar que para atingir valores significativos relacionados a corrosão a UR do ar deve ser superior a $80 \%$ com temperatura acima de $0^{\circ} \mathrm{C}$. A cidade de Recife apresenta valores muito próximos a estes.

A NBR 8800/2008 classifica o caso das exposições das estacas da ponte da Estrada Velha de Água Fria como C5-I muito alta (áreas industriais com alta umidade e atmosfera agressiva). É sabido que as patologias relacionadas à corrosão em estacas são gravíssimas, pois é a infraestrutura que absorve os esforços e cargas provenientes da superestrutura e pode, portanto, em situações limites, vir a ocasionar o colapso da ponte. Por isso, uma análise rigorosa do estaqueamento existente, seguida das providencias apropriadas para a correção dos danos observados, representa, sem dúvida, a mais importante recomendação deste texto.

\subsubsection{Plano de Vistorias e Manutenção}

A última versão da norma NBR 9452/ 2016-Inspeção de pontes, viadutos e passarelas de concreto - Procedimento, começou a vigorar em 08.04.2016 e específica os requisitos exigíveis para a realização de inspeção de pontes, viadutos e passarelas [8]. Com base nos procedimentos adotados pela referida norma, será possível estabelecer critérios para a manutenção, seja preventiva ou corretiva, sempre associado a um plano de gestão mais abrangentes das Obras de Arte Especiais onde a ponte estudada está inserida. Nesse sentido, deve-se elaborar um plano de manutenção periódica da ponte, com o planejamento, periodicidade e roteiro de vistorias, que devem fornecer todas as informações relevantes que deverão incluir toda a documentação existente sobre a ponte como o projeto e um relatório final. Todos os dados relacionados à superestrutura, mesoestrutura e infraestrutura da ponte, devem constar nas fichas da inspeção da obra, de modo a formar um cadastro que será utilizado ao longo de toda a vida útil da estrutura. No caso da cidade do Recife, onde está situada a ponte estudada neste artigo, faz-se necessário que sejam tomadas medidas urgentes relacionadas à implantação de um plano de gestão das pontes e viadutos que fazem parte da malha viária municipal. O plano deverá conter itens como vistorias periódicas, qualificação de equipe técnica, cadastro de obras, atualização de cadastro de pontes, e dotação orçamentaria para os serviços de manutenção e recuperação.
Se todos esses procedimentos de gestão da manutenção forem implantados, os índices de recuperações urgentes das estruturas das pontes vão reduzir consideravelmente e, em alguns casos, tais intervenções talvez sejam minimizadas ou até não necessárias. Um resultado imediato será o aumento da vida útil das estruturas e a redução dos transtornos causados com interdições parciais ou totais de pontes para a realização dos serviços de recuperação que sempre acarretam mudanças na rotina da população que utiliza tais equipamentos públicos. Porém, o maior ganho será garantir que o patrimônio construído da cidade seja devidamente preservado de modo a melhorar a mobilidade urbana e a segurança da população que usa diariamente os equipamentos públicos.

Este artigo, mesmo se tratando de um trabalho acadêmico, tem também, a intenção de contribuir para a melhoria da conservação das Obras de Arte Especiais da cidade do Recife por meio das análise e recomendações que fazem parte do texto.

\section{Referências}

[1] A.J. Bogo. Limitações quanto aos parâmetros de desempenho térmico e estratégias bioclimáticas recomendadas pela norma brasileira de desempenho térmico de habitações de interesse social. http://www.usp.br/nutau/CD/30.pdf, Mar. 2005.

[2] Bridge Engineering Handbook: Construction and Maintenance. 2 ed. Nova York: CRC Press, 2014.

[3] Sinaenco. Infraestrutura de Pernambuco: Prazo de validade vencido. www.sinaenco.com.br.

[4] M.H. F. de Medeiros. J.J. O. Andrade. P. Helene. Durabilidade e vida útil das estruturas de concreto. In. C. C. Isaia (ed). Concreto: Ciência e Tecnologia. IBRACOM, 2011.

[5] A. Vitório. Pontes rodoviárias: Fundamentos, conservação e gestão. Recife: CREA-PE, 2002.

[6] R.C. Lins. Alguns aspectos originais do sítio urbano do Recife. In: L. Jatobá (org.). Estudos nordestinos sobre o crescimento urbano. Recife: Fundaj. Página 343, 1987.

[7] N.R. Beckwith. Corrosion Test Programme of Steel Piles in River Murray Swamp Land South Australia. Engineering and Water Supply Dept. South Australia: 1979.

[8] ABNT - Associação Brasileira de Normas Técnicas. NBR 9452: Vistorias de Pontes e Viadutos de Concreto, 2016. 